\title{
ChemComm
}

\section{Evidence of two-state reactivity in alkane hydroxylation by Lewis-acid bound copper-nitrene complexes $\dagger$}

Cite this: Chem. Commun., 2014, 50,9852

Received 16th May 2014, Accepted 8th July 2014

DOI: $10.1039 /$ c4cc03754e

www.rsc.org/chemcomm

\author{
Sarah-Luise Abram, $\ddagger^{a}$ Inés Monte-Pérez, $\ddagger^{a}$ Florian Felix Pfaff, ${ }^{a}$ Erik R. Farquhar ${ }^{b}$ \\ and Kallol Ray*a
}

The behavior of the Lewis-acid adducts of two copper-nitrene $[\mathrm{Cu}(\mathrm{NR})]^{+}$complexes in nitrene-transfer and $\mathrm{H}$-atom abstraction reactions have been demonstrated to depend on the nature of the nitrene substituents. Two-state reactivity, in which a singlet ground state and a nearby triplet excited-state both contribute, provides a useful model for interpreting reactivity trends of the two compounds.

Copper-nitrene intermediates have attracted much interest in organometallic chemistry because they are implicated as key intermediates in the copper catalyzed alkane hydroxylation and alkene epoxidation reactions. $^{1-9}$ To engineer further improved catalysts, there is a substantial impetus to characterize fully the active species of existing catalysts, including the relevant higher oxidation states, intermediates and transition states so as to establish the mechanism(s) by which they affect $\mathrm{C}-\mathrm{N}$ bond formation reactions. However, despite considerable interest, no copper-nitrene intermediates have been isolated to allow for clear mechanistic studies. ${ }^{9,10}$ In the absence of isolated examples of the proposed active intermediate, the mechanisms of copper-nitrene mediated aziridination and amination reactions have been elucidated by high-level quantum chemical calculations..$^{1-3,7-8}$ In these calculations two alternative, limiting, electronic valence-bond structures have been characterized, namely, (closed-shell singlet) $\left[\mathrm{Cu}^{\mathrm{III}}(\mathrm{NR})\right]^{+}$or (openshell triplet or singlet) $\left[\mathrm{Cu}^{\mathrm{II}}\left(\mathrm{NR}^{\bullet}\right)\right]^{+}$structures. While concerted aziridination reactions have been proposed to be favored on the closed-shell $\left[\mathrm{Cu}^{\mathrm{III}}(\mathrm{NR})\right]^{+}$singlet surface, ${ }^{8}$ amination reactions were suggested to proceed via a stepwise $\mathrm{H}$-atom abstraction/radical rebound (HAT/RR) pathway on the $\left[\mathrm{Cu}^{\mathrm{II}}\left(\mathrm{NR}^{\bullet}\right)\right]^{+}$triplet surface. ${ }^{1}$ Moreover, in cases where the singlet and triplet states were very

\footnotetext{
${ }^{a}$ Humboldt-Universität zu Berlin, Institut für Chemie, Brook-Taylor-Straße 2, D-12489 Berlin, Germany. E-mail: kallol.ray@chemie.hu-berlin.de; Fax: +49 3020937387; Tel: +493020937385

${ }^{b}$ Case Western Reserve University Center for Synchrotron Biosciences and Center for Proteomics and Bioinformatics, National Synchrotron Light Source, Brookhaven National Laboratory, Upton, NY-11973, USA

$\dagger$ Electronic supplementary information (ESI) available: Experimental and theoretical details. See DOI: 10.1039/c4cc03754e

₹qual contribution of the two authors.
}

close in energy, a mechanistic picture involving both the singlet and triplet pathways for the aziridination ${ }^{7}$ and amination ${ }^{1}$ reactions has also been proposed.

What is required to test the theoretically predicted reactivity patterns is more direct experimental evidence that systematically shows the effect of singlet/triplet splitting energy on the reactivity of a copper-nitrene species. Very recently, our group reported the spectroscopic characterization of a Lewis-acid adduct of a cationic copper-tosylnitrene $\left[\mathrm{Cu}^{\mathrm{II}}-\left(\mathrm{NTs}{ }^{\bullet}\right) \operatorname{Sc}(\mathrm{OTf})_{3}\right]$ species $(\mathbf{1}$; Ts = tosyl; Scheme 1), the electronic structure of which could be best described in terms of a $\mathrm{Cu}$ (II) ion antiferromagnetically coupled to a nitrene radical thereby stabilizing an open-shell singlet ground state. ${ }^{11}$ Reactivity studies revealed that this species aminates $\mathrm{sp}^{3} \mathrm{C}-\mathrm{H}$ bonds in substrates such as toluene and even cyclohexane in modest yields (21-35\%). In this communication we now report the Lewis-acid stabilization of a related copper-nitrene species $\left[\mathrm{Cu}^{\mathrm{I}}\right.$-(NMes$\left.{ }^{\bullet}\right)$ $\left.\mathrm{Sc}(\mathrm{OTf})_{3}\right]$ (2; Mes = mesityl; Scheme 1), where the electron withdrawing heteroatom Ts nitrene substituent of $\mathbf{1}$ is replaced by the electron donating Mes group in 2 . A comparative reactivity study between 1 and 2 shows that a two-state reactivity (TSR) model ${ }^{12,13}$ applies for the two compounds, in which a singlet ground state and a nearby triplet excited-state both contribute to the reactivity.
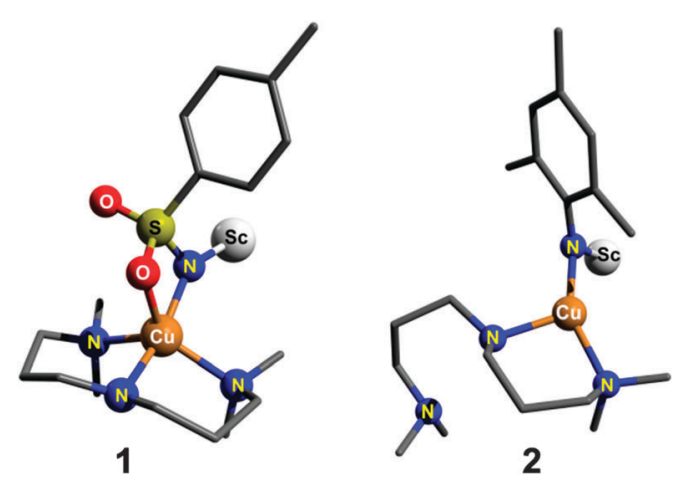

Scheme 1 DFT optimized structures of 1 and $\mathbf{2}$ in their ground singlet states. Triflates bound to scandium and the hydrogen atoms are not shown for clarity. 
Complex 2 is synthesized following the same procedure we reported previously for $1 ;^{11}$ the only difference is that we have now used an organic azide as a nitrene source in contrast to iminoiodane for the synthesis of $\mathbf{1}$. Thus the reaction of the previously synthesized $[\mathrm{Cu}(\mathrm{L} 1)]\left(\mathrm{BF}_{4}\right)^{14}$ complex (L1 = 3,3'-iminobis( $N, N$-dimethylpropylamine)) in $\mathrm{CH}_{2} \mathrm{Cl}_{2}$ with one equivalent of mesityl azide at $-90{ }^{\circ} \mathrm{C}$ in presence of 1.5 equivalent of scandium triflate for two hours generates the purple complex 2 with absorption maxima $\lambda_{\max }\left(\varepsilon_{\max }\right)$ centered at $560 \mathrm{~nm}\left(2000 \mathrm{~L} \mathrm{~mol}^{-1} \mathrm{~cm}^{-1}\right)$ and $670 \mathrm{~nm}$ $\left(1227 \mathrm{~L} \mathrm{~mol}^{-1} \mathrm{~cm}^{-1}\right.$ ) (Fig. 1). ${ }^{15}$ Total consumption of the azide in the reaction was confirmed by the disappearance of the $\nu\left(\mathrm{N}_{3}\right)$ stretch at $2123 \mathrm{~cm}^{-1}$ in the IR spectrum of the resultant solution of 2 (Fig. S1, ESI $\dagger$ ). Notably, the UV-Vis spectral changes associated with the formation of $\mathbf{2}$ are similar to that previously observed during the formation of $\mathbf{1} ;{ }^{11}$ the corresponding bands for $\mathbf{1}$ are at $530 \mathrm{~nm}\left(3500 \mathrm{~L} \mathrm{~mol}^{-1} \mathrm{~cm}^{-1}\right)$ and $750 \mathrm{~nm}\left(580 \mathrm{~L} \mathrm{~mol}^{-1} \mathrm{~cm}^{-1}\right)$, respectively (Fig. 1). ${ }^{1} \mathrm{H}-\mathrm{NMR}$ resonances of 2 are spread over a chemical shift range of 0 to $+10 \mathrm{ppm}$, thereby, demonstrating a singlet ground state $(S=0)$ similar to 1 ; the signals are, however, sharper compared to $\mathbf{1}$, which may point to a lesser contribution of the paramagnetic excited $S=1$ state in 2 (Fig. S2, ESI $\dagger$ ). Notably, the ${ }^{1} \mathrm{H}$-NMR splitting pattern of 2 is similar to $[\mathrm{Cu}(\mathrm{L} 1)]\left(\mathrm{BF}_{4}\right)$, which may also point to a similar geometry in the two cases.
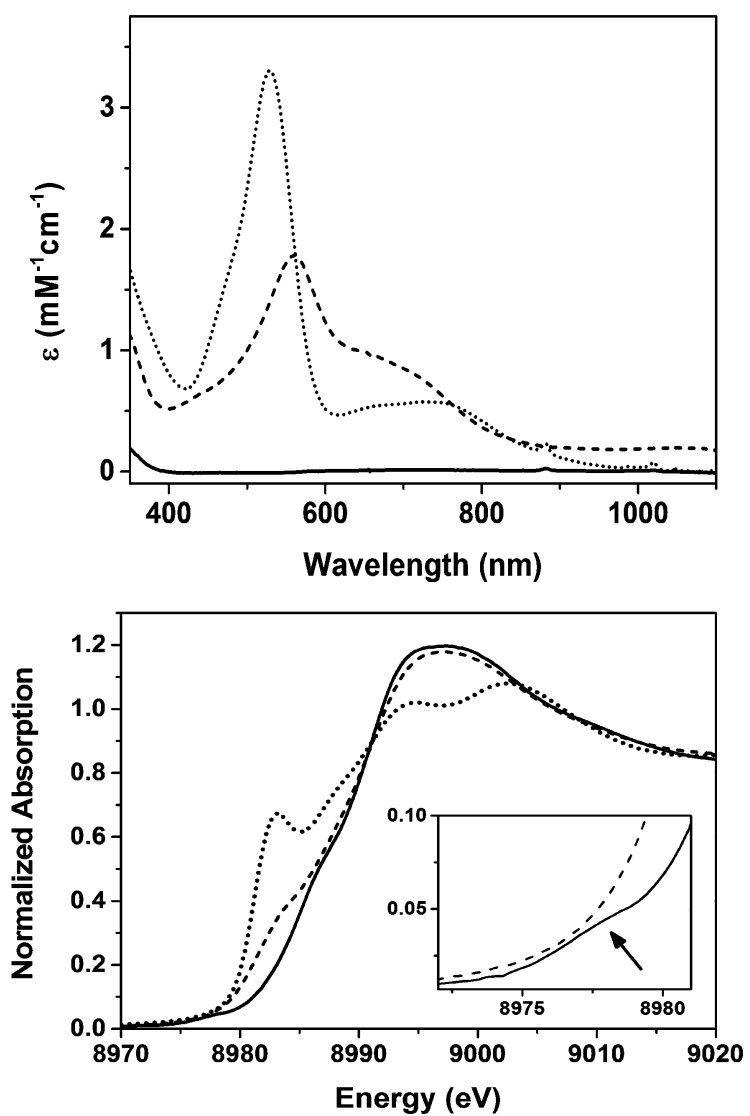

Fig. 1 Top: absorption spectra of $[\mathrm{Cu}(\mathrm{L} 1)]\left(\mathrm{BF}_{4}\right)$ (solid trace), 1 (dotted trace), and 2 (dashed trace) in $\mathrm{CH}_{2} \mathrm{Cl}_{2}$ at $-90{ }^{\circ} \mathrm{C}$; bottom: normalized $\mathrm{Cu}$ K-edge spectra for [Cu(L1)](BF $\left.{ }_{4}\right)$ (dotted line), 1 (solid line), and 2 (dashed line). The inset depicts an expansion of the pre-edge region; the pre-edge of $\mathbf{1}$ is depicted by the arrow.
2 performed a two-electron reduction process (Fig. S3, ESI $\dagger$ ) with a one electron reductant like decamethylferrocene $\left(\mathrm{Me}_{10} \mathrm{Fc}\right)$ at $-90{ }^{\circ} \mathrm{C}$ with the corresponding formation of $\mathrm{Cu}^{\mathrm{I}}$ (resultant solution is EPR silent) and decamethylferrocenium cation $\left(\mathrm{Me}_{10} \mathrm{Fc}^{+} ; 180 \%\right.$ yield); this confirmed that 2 is two oxidation levels (formal +3 oxidation state of copper) above $[\mathrm{Cu}(\mathrm{L} 1)]\left(\mathrm{BF}_{4}\right)$ and its initial yield is at least $90 \%$.

A comparison of the Cu K-edge X-ray absorption spectrum (XAS) of 2 with that of 1 and $[\mathrm{Cu}(\mathrm{L} 1)]\left(\mathrm{BF}_{4}\right)$ is shown in Fig. 1. Although the change in edge-shape and energies upon oxidation of $[\mathrm{Cu}(\mathrm{L} 1)]\left(\mathrm{BF}_{4}\right)$ to $\mathbf{2}$ is similar to the earlier published result for $\mathbf{1}$, some interesting differences in the spectra of $\mathbf{1}$ and $\mathbf{2}$ are apparent. First of all, complex 1 exhibits a weak pre-edge at $8978 \mathrm{eV}$ that is completely absent in 2. Moreover, in the spectrum of 2 a shoulder along the rising edge at $8981.5 \mathrm{eV}$, which is typically associated with a 1s-to-4p transition, ${ }^{16-18}$ is present that is absent in 1 . This may indicate a three coordinate trigonal planar (TP) geometry of copper in $2^{16,19}$ in contrast to the previous report ${ }^{11}$ of a distorted square pyramidal (SP) geometry in $\mathbf{1}$. However, the lack of pre-edge in 2 removes the one sure way of assigning the physical oxidation state of copper $\left(\mathrm{Cu}^{\mathrm{II}} v s\right.$.

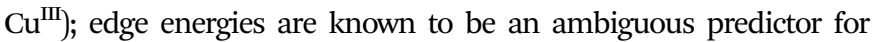
identifying whether a given complex is $\mathrm{Cu}^{\mathrm{II}}$ or $\mathrm{Cu}^{\mathrm{III}} .^{16}$

Complex 2 is very stable at $-90{ }^{\circ} \mathrm{C}(<5 \%$ decay in 2 hours $)$ and could be further tested as oxidant for hydrogen atom transfer (HAT) and nitrene transfer (NT) reactions. This provided us an opportunity to perform a direct reactivity comparison of the two copper-nitrene complexes, 1 and 2, bearing a common supporting ligand (L1), but different nitrene substituents (Ts in $\mathbf{1}$ and Mes in 2) in HAT and NT reactions carried out under identical conditions. Rate constants for nitrene-transfer to $\mathrm{PPh}_{3}$ and thioanisole or $\mathrm{C}-\mathrm{H}$ activation of 1,4-cyclohexadiene (CHD) and xanthene in $\mathrm{CH}_{2} \mathrm{Cl}_{2}$ at $-90{ }^{\circ} \mathrm{C}$ were obtained from the pseudo-first order fit of the decay of the absorption band at $560 \mathrm{~nm}$ (Fig. S4 and S5, ESI $\dagger$ ). Analysis of the reaction mixture for $\mathrm{CHD}$ and $\mathrm{PPh}_{3}$ reactions show the formation of benzene and $N$-(mesityl)-iminotriphenylphosphorane products, respectively, in near-quantitative yields; the resultant solution is EPR silent, which may indicate the formation of $\mathrm{Cu}(\mathrm{I})$. Second order rate constants $\left(k_{2}\right.$; Table 1$)$ for 2 were determined from the dependence of the first-order rate constants on substrate concentrations and then compared with the reported values ${ }^{11}$ for 1 . A contrasting reactivity pattern is apparent (Table 1), in which complex 2 is a better NT oxidant, while complex $\mathbf{1}$ is a better HAT agent.

DFT calculations (Fig. S6-S9 and Tables S1-S5, ESI $\dagger$ ) were carried out to understand the effect of the nitrene substituent on the reactivity of the $\left[\mathrm{L} 1 \mathrm{Cu}(\mathrm{NR}) \mathrm{Sc}(\mathrm{OTf})_{3}\right]^{+}(\mathrm{R}=\mathrm{Ts}$ for $\mathbf{1}$ and Mes for 2) complexes. Broken symmetry (BS) solutions ${ }^{20,21}$ were obtained for both 1 and 2 . For 2 the calculated ground state is an open-shell $\left[\mathrm{Cu}^{\mathrm{II}}\left(\mathrm{NMes}^{\bullet}\right)\right]^{+}$singlet with the excited triplet state lying $14.2 \mathrm{kcal}$ $\mathrm{mol}^{-1}$ higher in energy (Table S1, ESI $\dagger$ ). For complex 1 the calculated ground state is also an open-shell singlet $\left[\mathrm{Cu}^{\mathrm{II}}\left(\mathrm{NTs}^{\bullet}\right)\right]^{+}$ state; the excited BS triplet state (Table S1, ESI $\dagger$ ) was, however, found to be only $2.5 \mathrm{kcal} \mathrm{mol}^{-1}$ higher in energy. The smaller singlet-triplet gap of $\mathbf{1}$ is consistent with a recent DFT study on $\mathrm{Ni}$-nitrene complexes, ${ }^{2-24}$ which predicted that singlet ground states are favored when aryl/alkyl groups are on the nitrene, while the triplet is favored with electron withdrawing heteroatom groups. 
Table 1 Second order rate constants of 1 and $\mathbf{2}$ determined for the different substrates by kinetic studies using UV-Vis spectroscopy

\begin{tabular}{|c|c|c|}
\hline & 1 & 2 \\
\hline & $k_{2}\left(-90{ }^{\circ} \mathrm{C} ; \mathrm{L} \mathrm{mol}^{-1} \mathrm{~s}^{-1}\right)$ & $k_{2}\left(-90{ }^{\circ} \mathrm{C} ; \mathrm{L} \mathrm{mol}^{-1} \mathrm{~s}^{-1}\right)$ \\
\hline \multicolumn{3}{|l|}{ HAT } \\
\hline Xanthene & 0.3135 & 0.084 \\
\hline CHD & 0.1554 & 0.030 \\
\hline Toluene & 0.0051 & No reaction \\
\hline \multicolumn{3}{|l|}{ NT } \\
\hline $\mathrm{PPh}_{3}$ & 0.196 & 2.89 \\
\hline Thioanisole & No reaction & 0.5 \\
\hline
\end{tabular}

The optimized geometry of $\mathbf{2}$ in the experimentally observed singlet ground state reveals a three coordinate TP geometry (Scheme 1; Fig. S8 and Table S4, ESI $\dagger$ ) fully consistent with the Cu K-edge XAS study; the ligand L1 acts as a bidentate ligand with one of the terminal tertiary amine nitrogen atoms remaining out of the coordination sphere of $\mathrm{Cu}$. For 1 (Scheme 1; Fig. S6 and Table S2, ESI $\dagger$ ), in contrast, a SP geometry at copper is predicted for the BS singlet state, with a $k^{2}-\mathrm{N}, \mathrm{O}$ binding mode of the tosylnitrene ligand, consistent with the results of the previous calculations. ${ }^{8,11,25}$ Notably, the calculated $\mathrm{Cu}-\mathrm{N}$ distance (Table S1, ESI $\dagger$ ) in $\mathbf{1}$ of $1.95 \AA$ is significantly longer than the calculated distance for 2 of $1.84 \AA$, in their ground singlet states, thereby implying a more covalent $\mathrm{Cu}-\mathrm{N}$ bond in 2 .

Our DFT results provide a basis for interpreting the reactivity properties of $\mathbf{1}$ and $\mathbf{2}$ using a two-state reactivity model. In 1, the triplet state with a low activation barrier ${ }^{1}$ for HAT is low lying and easily accessible, which accounts for the higher HAT reactivity of $\mathbf{1}$ than 2. The NT reaction, in contrast, is thought to proceed predominantly on the singlet surface; ${ }^{8}$ the higher reactivity of 2 can then be possibly explained by the greater electrophilicity of the copper-nitrene unit in 2, owing to the larger contribution of the $\left[\mathrm{Cu}^{\mathrm{III}}(\mathrm{NR})\right]^{+}$valence-bond resonance form compared to $\mathbf{1}$.

In summary, we have demonstrated that the behavior of $\left[\mathrm{L} 1 \mathrm{Cu}(\mathrm{NR}) \mathrm{Sc}(\mathrm{OTf})_{3}\right]^{+}$( $\mathrm{R}=$ Ts for $\mathbf{1}$ and Mes for 2 ) complexes in both nitrene-transfer and $\mathrm{H}$-atom abstraction reactions depends on the nature of the nitrene substituent. Interestingly, whereas complex 2 is a better nitrene-transfer reagent than $\mathbf{1}$, an opposite reactivity trend is apparent for the $\mathrm{H}$-atom abstraction reactions. DFT calculations provide a plausible framework within which to rationalize these reactivity patterns. It is postulated that the observed HAT reactivity reflects the availability of two closely lying spin states for $\mathbf{1}$ and 2, the so-called TSR hypothesis, ${ }^{12,13}$ wherein the excited triplet state has a much lower reaction barrier than the ground singlet state. Thus, the tosyl substrate of $\mathbf{1}$ results in a decrease in the singlet-triplet gap and an increased participation of the triplet state in determining the rate of reaction. Hence, in this study we provide evidence that the TSR theory, well established for iron-oxo complexes, ${ }^{12,26}$ may also provide a framework for understanding reactivity of coppernitrenes. This study may therefore be of extreme importance in understanding the reactivity of mononuclear copper monooxygenases, ${ }^{27-30}$ where copper-oxo intermediates, which are isoelectronic to the presently described copper-nitrene species, have often been implicated as the active species responsible for oxidations.

We gratefully acknowledge financial support of this work from the Cluster of Excellence "Unifying Concepts in Catalysis" (EXC 314/1),
Berlin and COST Action CM1305 ECOSTBio. XAS data were obtained on NSLS beamline X3B (Brookhaven National Laboratory), with support from NIH Grant P30-EB-009998 and the U.S. Department of Energy. I.M.P thanks BIG-NSE for a scholarship.

\section{Notes and references}

1 D. N. Barman, P. Liu, K. N. Houk and K. M. Nicholas, Organometallics, 2010, 29, 3404-3412.

2 T. R. Cundari, A. Dinescu and A. B. Kazi, Inorg. Chem., 2008, 47, 10067-10072.

3 S. M. Tekarli, T. G. Williams and T. R. Cundari, J. Chem. Theory Comput., 2009, 5, 2959-2966.

4 M. J. B. Aguila, Y. M. Badiei and T. H. Warren, J. Am. Chem. Soc., 2013, 135, 9399-9406.

5 Y. M. Badiei, A. Dinescu, X. Dai, R. M. Palomino, F. W. Heinemann, T. R. Cundari and T. H. Warren, Angew. Chem., Int. Ed., 2008, 47, 9961-9964.

6 Y. M. Badiei, A. Krishnaswamy, M. M. Melzer and T. H. Warren, J. Am. Chem. Soc., 2006, 128, 15056-15057.

7 L. Maestre, W. M. C. Sameera, M. M. Díaz-Requejo, F. Maseras and P. J. Pérez, J. Am. Chem. Soc., 2013, 135, 1338-1348.

8 (a) P. Brandt, M. J. So, P. G. Andersson and P.-O. Norrby, J. Am. Chem. Soc., 2000, 122, 8013-8020; (b) P. Comba, C. Lang, C. Lopez de Laorden, A. Muruganantham, G. Rajaraman, H. Wadepohl and M. Zajaczkowski, Chem. - Eur. J., 2008, 14, 5313-5328.

9 R. Gephart and T. H. Warren, Organometallics, 2012, 31, 7728-7752. 10 A copper bis nitrene complex has been structurally characterized (F. Dielmann, D. M. Andrada, G. Frenking and G. Bertrand, J. Am. Chem. Soc., 2014, 136, 3800-3802), but no reactivity study is reported.

11 S. Kundu, E. Miceli, E. Farquhar, F. F. Pfaff, U. Kuhlmann, P. Hildebrandt, B. Braun, C. Greco and K. Ray, J. Am. Chem. Soc., 2012, 134, 14710-14713.

12 D. Usharani, D. Janardanan, C. Li and S. Shaik, Acc. Chem. Res., 2013, 46, 471-482.

13 D. Schröder, M. C. Holthausen and H. Schwarz, J. Phys. Chem. B, 2004, 108, 14407-14416.

14 H.-C. Liang, C. X. Zhang, M. J. Henson, R. D. Sommer, K. R. Hatwell, S. Kaderli, A. D. Zuberbühler, A. L. Rheingold, E. I. Solomon and K. D. Karlin, J. Am. Chem. Soc., 2002, 124, 4170-4171.

15 Complex 2 is EPR silent. However, when the reaction is performed in the absence of scandium a new species 3 is formed which shows a typical Cu(II) EPR signal (Fig. S10, ESI $\dagger$ ). Although further characterization of $\mathbf{3}$ is not performed we assign it to the copper(II)-amidate complex $\left[\mathrm{L} 1 \mathrm{Cu}^{\mathrm{II}}(\mathrm{HNMes})\right]^{+}$based on our previous study.

16 L. S. Kau, D. J. Spira-Solomon, J. E. Penner-Hahn, K. O. Hodgson and E. I. Solomon, J. Am. Chem. Soc., 1987, 109, 6433-6442.

17 J. L. Dubois, P. Mukherjee, T. D. P. Stack, B. Hedman, E. I. Solomon and K. O. Hodgson, J. Am. Chem. Soc., 2000, 122, 5775-5787.

18 P. J. Donoghue, J. Tehranchi, C. J. Cramer, R. Sarangi, E. I. Solomon and W. B. Tolman, J. Am. Chem. Soc., 2011, 133, 17602-17605.

19 N. P. Mankad, W. E. Antholine, R. K. Szilagyi and J. C. Peters, J. Am. Chem. Soc., 2009, 131, 3878-3880.

20 L. Noodleman and J. G. Norman, J. Chem. Phys., 1979, 70, 4903-4906.

21 L. Noodleman, J. Chem. Phys., 1981, 74, 5737-5743.

22 T. R. Cundari and G. R. Morello, J. Org. Chem., 2009, 74, 5711-5714.

23 T. R. Cundari and S. Vaddadi, THEOCHEM, 2006, 801, 47-53.

24 T. R. Cundari, J. O. C. Jimenez-Halla, G. R. Morello and S. Vaddadi, J. Am. Chem. Soc., 2008, 130, 13051-13058.

25 L. E. Grove, J. Xie, E. Yikilmaz, A.-F. Miller and T. C. Brunold, Inorg. Chem., 2008, 47, 3978-3992.

26 C. V. Sastri, J. Lee, K. Oh, Y. J. Lee, J. Lee, T. a. Jackson, K. Ray, H. Hirao, W. Shin, J. a. Halfen, J. Kim, L. Que, S. Shaik and W. Nam, Proc. Natl. Acad. Sci. U. S. A., 2007, 104, 19181-19186.

27 K. Ray, F. Heims and F. F. Pfaff, Eur. J. Inorg. Chem., 2013, 3784-3807.

28 K. Yoshizawa, N. Kihara, T. Kamachi and Y. Shiota, Inorg. Chem., 2006, 45, 3034-3041.

29 A. Crespo, M. A. Martí, A. E. Roitberg, L. M. Amzel and D. a. Estrin, J. Am. Chem. Soc., 2006, 128, 12817-12828.

30 S. Hong, S. M. Huber, L. Gagliardi, C. C. Cramer and W. B. Tolman, J. Am. Chem. Soc., 2007, 129, 14190-14192. 